\title{
Author Correction: Apolipoprotein J is a hepatokine regulating muscle glucose metabolism and insulin sensitivity
}

\author{
Ji A. Seo (1), Min-Cheol Kang (D, Won-Mo Yang, Won Min Hwang (D), Sang Soo Kim (1), Soo Hyun Hong, \\ Jee-In Heo (D), Achana Vijyakumar, Leandro Pereira de Moura (D), Aykut Uner (D), Hu Huang (D), Seung Hwan Lee (D), \\ Inês S. Lima, Kyong Soo Park (D), Min Seon Kim (D), Yossi Dagon, Thomas E. Willnow (D, Vanita Aroda, \\ Theodore P. Ciaraldi 1 , Robert R. Henry \& Young-Bum Kim (1)
}

Correction to: Nature Communications https://doi.org/10.1038/s41467-020-15963-w, published online 24 April 2020.

The original version of this Article contained errors in the author affiliations.

Kyong Soo Park and Young-Bum Kim were incorrectly associated with the Research Group of Food Processing, Korea Food Research Institute, Wanju-gun, Jeollabuk-do, Korea.

Kyong Soo Park was associated with Department of Molecular Medicine and Biopharmaceutical Sciences, Graduate School of Convergence Science and Technology, Seoul National University, Seoul Korea.

This has now been corrected in both the PDF and HTML versions of the Article.

Published online: 05 May 2020

\footnotetext{
(c) (i) Open Access This article is licensed under a Creative Commons Attribution 4.0 International License, which permits use, sharing, adaptation, distribution and reproduction in any medium or format, as long as you give appropriate credit to the original author(s) and the source, provide a link to the Creative Commons license, and indicate if changes were made. The images or other third party material in this article are included in the article's Creative Commons license, unless indicated otherwise in a credit line to the material. If material is not included in the article's Creative Commons license and your intended use is not permitted by statutory regulation or exceeds the permitted use, you will need to obtain permission directly from the copyright holder. To view a copy of this license, visit http://creativecommons.org/licenses/by/4.0/.
}

(c) The Author(s) 2020 